\title{
Voltage Control of PV-Rich LV Networks: OLTC-Fitted Transformer and Capacitor Banks
}

\author{
Chao Long, Member, IEEE and Luis F. Ochoa, Senior Member, IEEE
}

\begin{abstract}
Due to the increasing adoption of domestic photovoltaic (PV) systems, the use of technologies such as on-load tap changer (OLTC)-fitted transformers, capacitor banks, and remote monitoring are being considered to mitigate voltage issues, particularly in European-style low voltage (LV) networks. Depending on the control strategy, however, the effects on customer voltages and control actions (e.g., tap changes or capacitor switching) can vary significantly. This work presents a framework to assess the performance of different OLTC-based control strategies in terms of voltage compliance with the standard BS EN50160 and the number of control actions. Three control strategies are proposed: constant set-point (CSC), time-based (TBC) and remote monitoring-based (RMC). A week-long Monte Carlo analysis is carried out considering a real UK LV network, three-phase power flows, different PV penetrations and seasonality. Results show that the TBC outperforms the CSC but at the expense of more tap changes. Due to the enhanced visibility, the RMC significantly increases the PV hosting capacity whilst limiting tap operations. Finally, when feeders have contrasting voltage issues, capacitor banks are found to provide additional flexibility and allow higher PV penetrations. These findings are expected to help the industry determining the benefits from OLTC-based solutions in future LV networks.
\end{abstract}

Index Terms--capacitor banks, low voltage distribution network, on-load tap changer, photovoltaic, voltage control.

\section{INTRODUCTION}

C OLAR photovoltaic (PV) technologies are one of the fastest growing renewable energy sources being integrated worldwide onto electrical power systems. In the UK, the current installed capacity of PV systems is approximately $5 \mathrm{GW}$ of which more than half corresponds to residential-scale connections (less than $4 \mathrm{kWp}$ ) [1], [2]. By 2020, this figure is expected to reach 10 to $20 \mathrm{GW}$. The low voltage (LV) distribution networks $(400 \mathrm{~V})$, to which these small-scale PV systems are connected, are already facing technical challenges in areas where clusters of PV installations exist. Voltage rise is one of the dominant issues that limit the ability of LV networks to host high PV penetrations.

In the UK and in many countries in the world with Europeanstyle network designs, LV circuits are typically equipped with off-load tap changers which means that the fine tuning of the ratio between the primary and secondary of the transformers can only be changed when disconnecting the load. To extend

The authors are with the Electrical Energy and Power Systems (EEPS) Group, School of Electrical and Electronic Engineering, The University of Manchester, Manchester M13 9PL, UK. (E-mail: chao.long.10@gmail.com; the 'on load' flexibility in terms of voltage management closer to the LV customers, the adoption of on-load tap changer (OLTC)-fitted distribution transformers is increasingly being considered, particularly in the context of residential-scale PV systems [3]-[7]. However, depending on the control strategy, tap operations can be significant, leading to the wear and tear of the OLTC [3], [4]. Therefore, an adequate OLTC control strategy should be used to ensure voltages are within statutory limits whilst minimizing tap operations so as to reduce the maintenance/overhaul cost incurred by the Distribution Network Operator (DNO).

Most of the studies found in the literature focus on control strategies that integrate the operation of LV OLTC-fitted transformers and other controllable elements. The technical and economic benefits of controlling active and reactive power of residential-scale PV systems as well as OLTC-fitted transformers were assessed in [5], [6]. This, however, was limited to only a few snapshots of demand and generation rather than a time-series analysis. In terms of impacts, only the voltage at the 'weakest' point was quantified rather than considering voltages at all customer connection points. The number of tap operations was not quantified. In [7], a sensitivity-based coordinated control of battery energy storage system and OLTC was proposed to increase the network's ability to host low carbon technologies. The effects on tap operations were quantified but the adopted time-series analysis was limited to six hours. These studies did not provide a clear quantification of the benefits from the use of the OLTC and the different strategies that could be adopted to control voltages over significant periods of time.

The performance of an LV OLTC-fitted transformer was analyzed in [8] considering a load-based control algorithm. The OLTC set-point was changed depending on the total load variation. This method, however, requires some understanding of the impedances of the feeders to approximate suitable setpoints. Similarly, in [3] and [4], an allowable voltage range at the busbar was analyzed and adopted as the control input for the OLTC in order to reduce tap operations. This voltage range was determined by the characteristics of the LV feeders, i.e., number of customers, impedance, PV penetration. Consequently, these control strategies are not generic and, thus, need to be tuned for each network where they will be deployed - making them less practical.

luis_ochoa@ieee.org). This work has been partly funded by Electricity North West Limited (ENWL), UK, through the Ofgem's Low Carbon Networks Fund Tier 1 "Low Voltage Integrated Automation (LoVIA)", 2014-2015. 
Furthermore, all the above studies did not consider LV feeders having contrasting voltage issues (i.e., significant voltage rise and drop simultaneously in different feeders). The tap operation of the OLTC will influence voltages at all LV feeders. While this performs well in a network where all feeders behave similarly due to the distribution of PV systems and/or loads among them, it would not be able to effectively manage voltages when feeders have contrasting voltage issues.

It is also important to highlight that, to adequately quantify the performance of a voltage control strategy, the uncertainties surrounding the residential PV generation and demand (i.e., location, size, and variability) need to be catered for. In addition, the particular characteristics of UK residential LV networks (i.e., three-phase four-wire feeders with mainly single-phase connected loads), which are also similar in other European countries (e.g., The Netherlands, Finland), Oceania (e.g., Australia, New Zealand) and South America (e.g., Brazil, Colombia), need to be considered. In [9], an assessment of the benefits from using OLTC-fitted transformers in UK LV networks compared to the network reinforcements was presented. However, the detailed operational aspects of the OLTC such as bandwidth and control cycles were not considered. The latter was investigated in [10] to show the performance of different OLTC-based control strategies.

This paper presents a framework to assess the benefits from adopting different OLTC-based control strategies in terms of their ability to increase the PV hosting capacity of LV networks. Three control strategies are proposed: constant set-point, timebased and remote monitoring-based. The latter, in particular, enables the set-point (i.e., voltage target at the busbar) to follow the trend of the busbar voltage with an adequate compensation, which is determined by the remote monitoring voltages. Furthermore, for cases when LV feeders have contrasting voltage issues, further flexibility is provided by adopting capacitor banks operating on a coordinated but yet decentralized mode. This remote monitoring-based OLTC control with multiple capacitor banks is currently being trialed in two UK residential LV networks as part of the "Low Voltage Integrated Automation (LoVIA)" project [11].

Here, a week-long (1-minute resolution) Monte Carlo analysis is carried out considering a real UK residential LV network (350+ customers), three-phase power flows, different PV penetrations and seasonality. To assess the performance of the control strategies, the voltage compliance with the standard BS EN50160 and the number of control actions are used as key metrics.

\section{PROBLEM Formulation}

LV feeders in European-style distribution networks are typically operated in a radial fashion and constructed in a treelike topology rooted at the transformer. Fig. 1 illustrates a single-line diagram of one LV feeder with an OLTC-fitted transformer, capacitor banks, and PV systems. There are $m$ nodes indexed by $i=1,2, \ldots, m$. The real and reactive power flow, $P_{i}$ and $Q_{i}$, can be expressed by

$$
P_{i}=\left(P_{L_{i+1}}-P_{G_{i+1}}\right)+P_{i+1}
$$

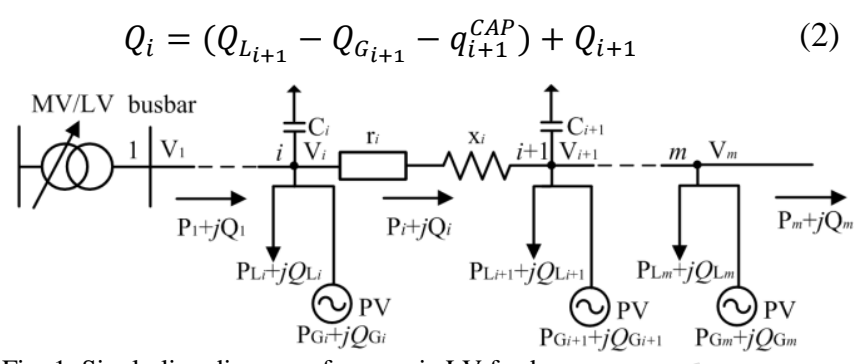

Fig. 1. Single-line diagram of a generic LV feeder

$$
q_{i+1}^{C A P}=c_{i+1, t} Q_{i+1}^{C A P} .
$$

where $P_{G_{i+1}}$ and $Q_{G_{i+1}}$ are the real and reactive power generated by the PV system installed at node $i+1 . Q_{G_{i+1}}$ can be positive or negative depending on the power factor (lagging or leading). In this work, all PV generations are considered to operate at unity power factor, and, hence, $Q_{G_{i+1}}$ is equal to zero. $q_{i+1}^{C A P}$ is the reactive power injected by the capacitor $C_{i+1} \cdot c_{i+1, t}$ is a binary indicator of the switch status of the capacitor banks at node $i+1$ at time instant $t(1-\mathrm{ON}, 0-\mathrm{OFF})$.

When the PV generation exceeds the local demand, power flows from the feeder upstream to the busbar resulting in voltage rise. To cope with this, the busbar voltage, $V_{1}$, can be adequately adjusted using the OLTC-fitted transformer.

However, in LV networks with multiple feeders, low voltages at the busbar can result in even lower voltages in those feeders with limited or no PV installation. Hence, suitably located capacitors can provide further flexibility to manage voltages across the LV network.

\section{A. OLTC Operational Model}

Similarly to an OLTC used in higher voltages, during its operation, the tap ratio is changed discretely to regulate the secondary (busbar) voltage, $V_{1}$, to achieve a set-point, $V_{\text {set }}$. When $V_{1}$ remains outside the corresponding bandwidth, $\varepsilon$, continuously for a time delay, $T_{d}$, the tap position is changed accordingly. The formulation of the OLTC operation is shown as follows:

$$
\begin{gathered}
e=V_{1}-V_{\text {set }} \\
\tau(t+1)=\left\{\begin{array}{lc}
\tau(t)+1, & \text { if } e>\frac{\varepsilon}{2} \text { and } \tau \geq 0 \\
\tau(t)-1, & \text { if } e<-\frac{\varepsilon}{2} \text { and } \tau \leq 0 \\
0, & \text { otherwise }
\end{array}\right. \\
f(e, \tau)=\left\{\begin{array}{lc}
1, & \text { if } e>\frac{\varepsilon}{2} \text { and } \tau>T_{d} \\
-1, & \text { if } e<-\frac{\varepsilon}{2} \text { and } \tau<-T_{d} \\
0, & \text { otherwise }
\end{array}\right. \\
n(t+1)=n(t)-d \cdot f(e(t), \tau(t)) .
\end{gathered}
$$

where the set-point is a constant or varying value depending on the control strategy, $e$ is the voltage difference between the actual busbar voltage and the set-point, $\tau$ is the counter, $n$ is the tap position, and $d$ is the number of required tap steps. 
Equations (4) to (7) state that $e$ is kept larger than $\varepsilon / 2$ (or smaller than $-\varepsilon / 2$ ) for a time delay (e.g., $2 \mathrm{~min}$ ), the OLTC will have a lowering (or increasing) tap action for $d$ steps. $d$ is an integer number and can be 1 for a single tap step or more than 1 for multiple tap steps.

To avoid any hunting effect, the chosen bandwidth, $\varepsilon$, has to be larger than the magnitude of the voltage change at the busbar for a single tap operation (one step), $V_{\text {onetap }}$, as shown in

$$
\varepsilon>V_{\text {onetap }}
$$

\section{B. Capacitor Operational Model}

Capacitor banks can be operated by different control modes, including current-based, voltage-based, kVAr-based, power factor-based, and time-based. Given the need to manage voltages, the voltage-based control is used in this work as the most direct approach.

The reactive power injection from a single capacitor will result in a voltage boost that will affect not only neighbouring nodes but also the LV busbar. Therefore, to avoid frequent switching actions or a hunting effect among devices, coordination should exist between capacitors and the OLTC.

A capacitor is switched $\mathrm{ON}$ when the voltage is lower than the pre-set "switch-on" value, $V_{\text {switch_on }}$, for a time delay of $T_{d_{-} \text {on }}$, and switched OFF when the voltage is higher than the pre-set "switch-off" value, $V_{\text {switch_off }}$, for a time delay of $T_{d_{-} \text {off }}$. The formulation of switching of the capacitor at node $i$ can be expressed by

$$
\begin{gathered}
e_{1}=V_{i, t}-V_{\text {switch_on }} \\
e_{2}=V_{\text {switch_off }}-V_{i, t} \\
c_{i, t}=\left\{\begin{array}{lr}
1, & \text { if } e_{1}<0 \text { and } \tau_{C}>T_{d_{-} \text {on }} \\
0, & \text { if } e_{2}<0 \text { and } \tau_{C}>T_{d_{-} \text {off }} \\
c_{i, t-1}, & \text { otherwise }
\end{array}\right. \\
\varepsilon_{C}=V_{\text {switch_off }}-V_{\text {switch_on }}\left(\varepsilon_{C}>0\right) .
\end{gathered}
$$

where $\tau_{C}$ is the counter starting from the instant when $e_{1}<0$ or $e_{2}<0 . \varepsilon_{C}$ is defined as the deadband.

The switch-on and switch-off voltages have to be set in a coordinated fashion. To achieve this, first the voltage boost at node $i$ provided by the $n$th capacitor, $C_{n}$, is defined by the term $\Delta \mathrm{V}_{i}^{C_{n}}$. When a network has only one capacitor, the deadband, $\varepsilon_{C}$, has to be larger than the corresponding voltage boost at the connection point (CP). This constraint is shown in

$$
\varepsilon_{C}>\Delta \mathrm{V}_{C P_{1}}^{C_{1}} .
$$

When a network has multiple capacitor banks, to allow all capacitor banks being able to switch ON simultaneously, the set deadband for each capacitor bank, $\varepsilon_{C n}$, has to be larger than the sum of all the voltage boosts, at the corresponding CP.

Assuming there are $\mathrm{N}$ capacitor banks connected to the network, this constraint is shown in

$$
\varepsilon_{C n}>\sum_{k=1}^{N} \Delta \mathrm{V}_{C P_{n}}^{C_{k}}
$$

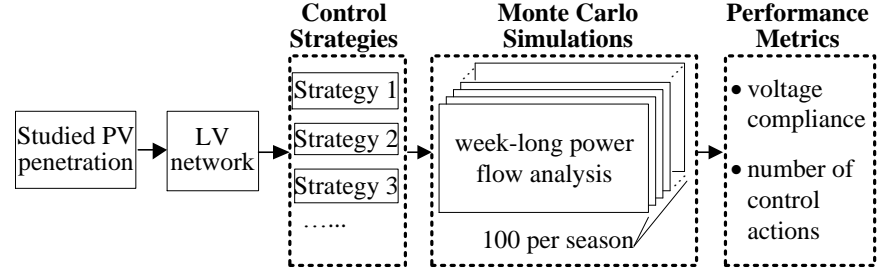

Fig. 2. Flow chart for the performance assessment framework

Here, the capacitors are operated on a coordinated but yet decentralized mode, i.e., based on the voltages at the point of connection. Therefore, no communications are required between the OLTC and the capacitor banks.

\section{METHODOLOGY}

\section{A. Performance Metrics}

An effective voltage control strategy is one that effectively keeps voltages at the customer connection points within the statutory limits. In UK LV networks these limits are $+10 /-6 \%$ of nominal, i.e., $253 \mathrm{~V}(1.10 \mathrm{pu})$ and $216 \mathrm{~V}$ (0.94 pu) line-toneutral $(\mathrm{L}-\mathrm{N})$. Compliance with these limits is checked according to the standard BS EN50160 [12] adapted to the UK context, by which $95 \%$ of the voltages (10-min average rms values) within a week must be between 1.10 and $0.94 \mathrm{pu}$, and never outside 1.10 and $0.85 \mathrm{pu}$. Therefore, in this work weeklong three-phase power flow analyses with 1-minute resolution are carried out to quantify this performance metric.

To capture the effects that different control strategies might have on the maintenance cost or life span of the controllable elements, the number of control actions (i.e., tap changes and capacitor switching) are considered as another metric.

\section{B. Monte Carlo Analysis}

Given the uncertainties surrounding residential demand and PV generation, to adequately quantify the performance of different control strategies, a Monte Carlo-based method previously developed in [13] is applied here. This allows managing the complexity from multiple stochastic variables, particularly when adopting realistic load and PV models (section V). Multiple individual power flow analyses for each of the PV penetrations are investigated. For each of the individual power flows, the locations and profiles of loads and PV systems are randomly allocated following realistic distributions. The performance metrics are then quantified and stored for the particular simulation. Finally, based on these performance metrics, the performance of different control strategies are analyzed.

For a week-long power flow analysis, first, the load profile of each individual LV customer is created for each of the seven days considering the type of day (i.e., weekday/weekend, season) and occupancy. The location and size of PV systems are then randomly selected. Different daily PV profiles for the same season are used for the seven days. Finally, this weekly power flow analysis is repeated multiple times (100 in this case) per season and per PV penetration level.

\section{Performance Assessment Framework}

Fig. 2 shows the adopted framework to assess the 
performance of different control strategies. For the studied PV penetration and a given control strategy, the week-long threephase power flow analyses are carried out applying the Monte Carlo analysis. This allows obtaining the performance metrics in a probabilistic manner, i.e., catering for the various uncertainties.

\section{OLTC-BASED CONTROL STRATEGIES}

\section{A. UK Distribution Transformer and OLTC}

In the UK, the distribution transformer ratio is typically $11 \mathrm{kV}$ (or $6.6 \mathrm{kV}$ ) to $433 \mathrm{~V}$. The off-load tap changer capability range is $\pm 5 \%$ ( 5 tap positions, $2.5 \%$ per step) and is commonly set to the nominal tap position $(\sim 250 \mathrm{~V}$ L-N $)$. The OLTC studied in this work has a range of $\pm 8 \%$ with $2 \%$ per tap step, i.e., 9 tap positions in total, hence providing a much wider voltage regulation capability compared to the business as usual off-load tap changer. This OLTC design is commercially available [14] and has been used in the LoVIA project. Assuming that the voltage at the primary of the transformer is the nominal (e.g., $11 \mathrm{kV}$ line-to-line), the L-N voltages at the busbar will be 231.5, 235.8, 240.4, 245.1, 250.0, 255.1, 260.4, 265.9 and $271.7 \mathrm{~V}$ corresponding to the tap positions from 1 to 9.

\section{B. Constant Set-point Control (CSC)}

The principle for this control strategy is that the set-point keeps a fixed value, as shown in

$$
V_{\text {set }}=V_{0} \text {. }
$$

There will still be tap operations as the OLTC will change the position to maintain the busbar voltage at, or close to, the set-point. For this control strategy, 240.2 V L-N, i.e., 1.04 pu, is taken as the set-point. This value provides extra headroom for PV generation compared to the business as usual approach $(\sim 250 \mathrm{~V}$ using the off-load tap changer with $1.0 \mathrm{pu}$ at the primary side) whilst coping with potential voltage drops during peak demand.

\section{Time-Based Control (TBC)}

In the UK, voltage rise due to PV systems happens because of its coincidence with minimum demand. This PV generation does not extend considerably to hours of peak demand (e.g., 17:00 to 20:00). Hence, by changing the set-point according to the time it is possible to adopt a less conservative value during minimum demand and a more conservative one during peak, as shown in

$$
V_{\text {set }}=\left\{\begin{array}{l}
V_{1} \text { peak demand } \\
V_{2} \text { minimum demand }
\end{array}\right.
$$

The set-point voltages for different periods of the day adopted for the TBC strategy are shown in Table I. This also considers the duration of daylight for the different seasons in the North West of England (case study).

\section{Remote Monitoring-Based Control (RMC)}

\section{1) Architecture}

A schematic of the proposed RMC architecture is shown in Fig. 3. Three feeders are shown for illustration purposes. The

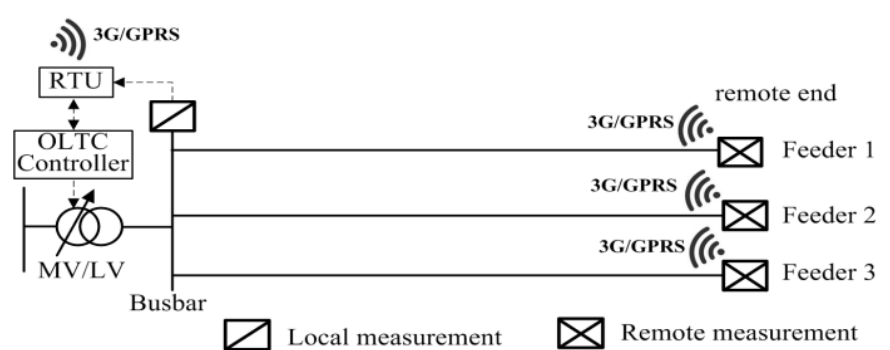

Fig. 3. Remote monitoring-based control architecture

TABLE I

\begin{tabular}{|c|c|c|}
\hline Season & Time & Set-point Voltage \\
\hline \multirow{2}{*}{ Summer } & $6: 00$ to $16: 59$ & $237.9 \mathrm{~V}(1.03 \mathrm{pu})$ \\
\hline & $00: 00$ to $5: 59$ and $17: 00$ to $23: 59$ & $242.5 \mathrm{~V}(1.05 \mathrm{pu})$ \\
\hline \multirow{2}{*}{ Spring/Autumn } & $7: 00$ to $16: 59$ & $237.9 \mathrm{~V}(1.03 \mathrm{pu})$ \\
\hline & $00: 00$ to $6: 59$ and $17: 00$ to $23: 59$ & $242.5 \mathrm{~V}(1.05 \mathrm{pu})$ \\
\hline \multirow{2}{*}{ Winter } & $8: 30$ to $15: 59$ & $237.9 \mathrm{~V}(1.03 \mathrm{pu})$ \\
\hline & $00: 00$ to $8: 29$ and $16: 00$ to $23: 59$ & $242.5 \mathrm{~V}(1.05 \mathrm{pu})$ \\
\hline
\end{tabular}

TBC: SET-POINT FOR DIFFERENT PERIODS OF THE DAY

TABLE II

\begin{tabular}{|c|c|c|c|c|c|c|}
\hline \multirow{5}{*}{$\begin{array}{c}\text { E Orange } \\
\text { Green } \\
\text { Orange }\end{array}$} & \multirow{3}{*}{$\begin{array}{c}>253 \\
(248,253]\end{array}$} & $\begin{array}{c}\text { Red } \\
>253\end{array}$ & \multirow[t]{2}{*}{$\begin{array}{c}\text { Orange } \\
(248,253]\end{array}$} & \multirow[t]{3}{*}{$\begin{array}{c}\text { Maximum } \\
\text { Green } \\
{[221,248]}\end{array}$} & \multirow[t]{4}{*}{$\begin{array}{c}\text { Orange } \\
{[216,221)}\end{array}$} & \multirow[t]{2}{*}{$\begin{array}{l}\text { Red } \\
<216\end{array}$} \\
\hline & & +3 & & & & \\
\hline & & +2 & +2 & & & \\
\hline & {$[221,248]$} & +2 & +1 & 0 & & \\
\hline & {$[216,221)$} & +1 & 0 & -1 & -2 & \\
\hline Red & $<216$ & 0 & -1 & -2 & -2 & -3 \\
\hline
\end{tabular}

RMC: COMPENSATING FACTOR ACCORDING TO THE VOLTAGE ZONES

remote voltage monitoring devices are installed at the end points of the LV feeders. These monitoring devices send, via wireless communications (e.g., 3G/GPRS), the voltage data to a remote terminal unit (RTU) located at the substation. In this case, the RTU is a physical device in which the control logic is coded. Based on this logic, the RTU can then send to the tap changer controller a command to produce an adequate set- point that ultimately alleviates any potential issue.

\section{2) Control Logic}

For the RMC, the set-point is changed according to the measured voltages at the busbar (local) as well as the end points (remote). Consequently, if needed, this set-point is changed as frequently as the control cycles.

Considering the locally monitored busbar voltage as a reference ( $V_{\text {busbar } i}$, average of the control cycle), a compensating voltage, $\Delta V_{i}$, for the control cycle $i$ is calculated taking into account the remote monitoring voltages. The new set-point, $V_{\text {set } i+1}$, is then obtained by the difference between the monitoring busbar voltage and the compensating voltage, $\Delta V_{i}$, as shown in (17). This process takes place every control cycle (e.g., every 5 minutes, every 15 minutes, etc.).

$$
V_{\text {set } i+1}=V_{\text {busbar } i}-\Delta V_{i}
$$

To calculate the compensating voltage, this work proposes the use of three voltage zones, as presented by

$$
\text { Zone }=\left\{\begin{array}{cc}
\text { Red } & \left(0, V_{l b}\right) \text { or }\left(V_{u b},+\infty\right) \\
\text { Orange } & {\left[V_{l b}, V_{l b}+\delta V\right) \text { or }\left(V_{u b}-\delta V, V_{u b}\right]} \\
\text { Green } & {\left[V_{l b}+\delta V, \quad V_{u b}-\delta V\right]} \\
\left(2 \delta V<V_{u b}-V_{l b}\right) .
\end{array}\right.
$$


where $V_{l b}$ and $V_{u b}$ are the lower and upper statutory voltage limits. $\delta V$ is a safety margin so actions can be taken before reaching the limits.

Equation (18) shows that, if voltages at the end points breach the statutory limits (e.g., either higher than $253 \mathrm{~V}$ or lower than $216 \mathrm{~V}$ for UK LV networks), they are in the red zone. When voltages are close to the boundary within a certain range (e.g., with $\delta V$ equal to 0.02 the relevant voltages are from 248 to $253 \mathrm{~V}$ and from 216 to $221 \mathrm{~V}$ ), then they are considered to be in the orange zone. Finally, the remaining voltages correspond to the green zone (e.g., between 221 and $248 \mathrm{~V}$ ). These zones can be tuned to different statutory limits adopted in other countries.

By determining how far the monitoring end-point voltages, in particular the maximum and minimum values, are from the ideal range (i.e., the green zone) it is possible to estimate the needed compensation of the busbar voltage. This estimation, however, has to consider the tap steps that the OLTC might require according to the adopted design, as shown in Table II.

Therefore, for a given control cycle $i$, first the voltage zones of the maximum and minimum of all the end point voltages are determined. The compensating voltage, $\Delta V_{i}$, is then obtained by multiplying the corresponding factor in Table II and $V_{\text {onetap }}$ equal to $4.6 \mathrm{~V}$ ( $2 \%$ tap step).

With the proposed approach voltages outside the ideal range (i.e., the green zone) are brought back to it with just enough compensation (Table II) to produce values close to the exceeded boundary (upper or lower). This, in turn, results in less tap changes than simpler approaches that calculate the required compensation using a single voltage target.

\section{E. Use of Capacitor Banks}

Capacitor banks (modelled as presented in section II) are used only in cases where LV feeders present contrasting voltage issues due to uneven PV penetrations among feeders.

\section{CAse Study}

In this section, first the modelling aspects of a real UK LV network are presented. Then, two case studies are presented and discussed adopting the proposed control strategies. Even and uneven PV penetrations among the corresponding feeders are investigated, demonstrating also the extended flexibility from using capacitor banks. The distribution system analysis software package OpenDSS and MATLAB are used to run the time-series three-phase power flows and the control strategies.

\section{A. Real UK LV Distribution Network}

The proposed methodology is applied to a real LV residential network (located in the North West of England). The $11 \mathrm{kV} / 400 \mathrm{~V}$ network is composed of six radially operated feeders (three-phase four-wire underground cables). The network topology is shown in Fig. 4, where the triangle represents the transformer (rated capacity $500 \mathrm{kVA}$ ). Different feeders are shown in different colors and each solid dot represents a customer. There are 49, 21, 30, 100, 68 and 83 customers, respectively, in the six feeders (i.e., 351 in total), all with single-phase connections. The number of customers per phase are shown in the label of the figure (phase $a, b, c$ ). The black rectangles at the end points of the feeders

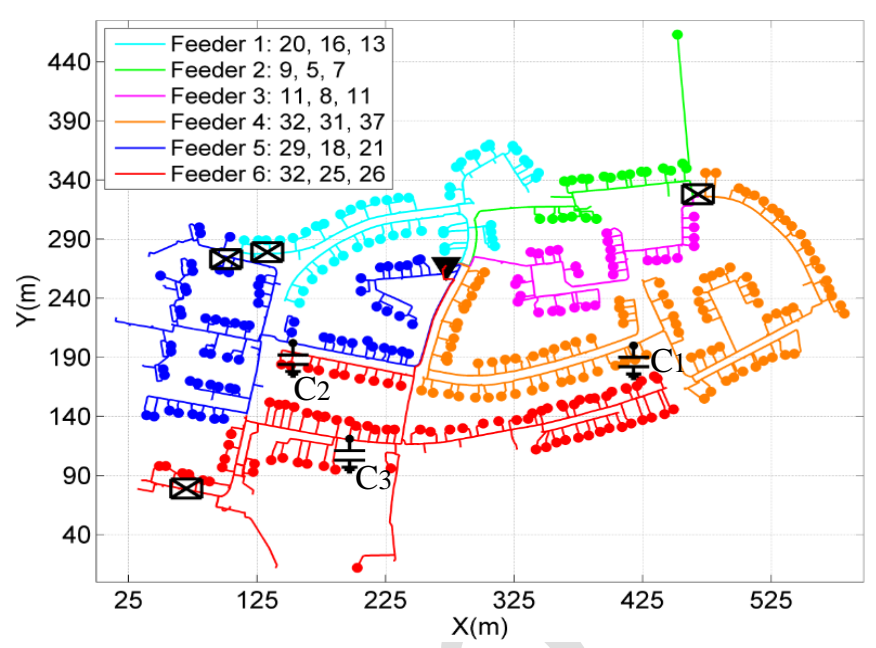

Fig. 4. Real UK LV distribution network

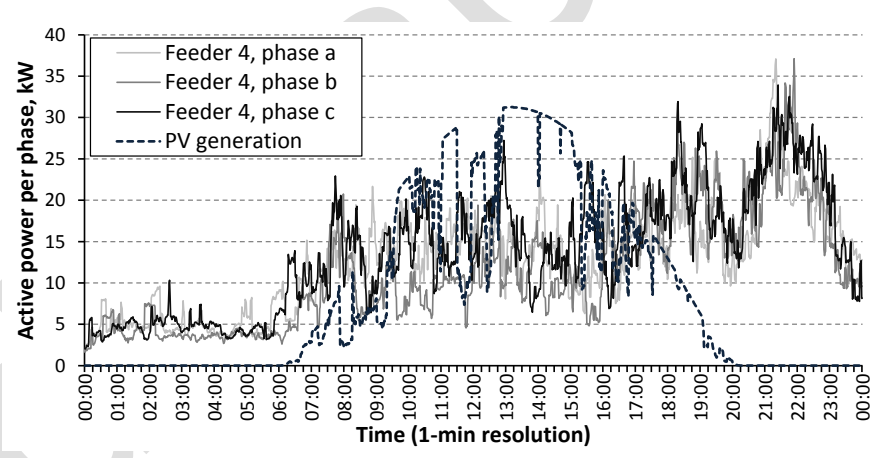

Fig. 5. Aggregated daily (weekday, July) load profile per phase for feeder 4 (100 customers) and aggregated PV generation (10 customers)

correspond to feasible locations for remote monitoring devices. Note that the end points for feeders 2, 3 and 4 are at a similar location (open point), i.e., only one black rectangle.

As part of the LoVIA project [11], the three feeders with the largest number of customers (feeders 4, 5 and 6) were selected to have installed three-phase capacitors. The location was chosen based on the voltage boost to be provided by each capacitor (the further from the busbar the more beneficial to customers) and the capacity of the underground cables due to the reactive power injections (the further from the busbar the smaller the cables). Consequently, the middle point of the feeders $\left(C_{1}, C_{2}\right.$ and $\left.C_{3}\right)$ were chosen as shown in Fig. 4. More rigorous approaches for the location of capacitors can also be adopted (e.g., [15]-[17]), however, practical aspects such as space availability should also be considered.

\section{B. Load and Photovoltaic Profiles}

The tool developed by the Centre for Renewable Energy Systems Technology (CREST) [18] is used for modelling the domestic load profiles given its high time-granularity (one minute). The load of each individual household is modelled realistically considering type of day, seasonality, occupancy and the associated use of electrical appliances [18].

For each feeder of the network, the adopted number of occupants per household follows UK statistics [19], i.e., the percentage of houses with 1, 2, 3 and more than 4 persons are $29,35,16$ and $20 \%$, respectively. 
Once the occupant number for a household is determined, the load profiles are created adopting a particular day of the year. For the PV systems, the same day is adopted and the corresponding generation is produced also using the tool. Due to the relatively small area of LV networks, for a given day, all PV systems are considered to have the same generation profile. The nominal capacity of the PV systems is randomly selected from a range of 2.0 to $3.5 \mathrm{kWp}$. This is aligned with the UK Engineering Recommendation G83/1 by which single-phase connected distributed generation is limited to 16A [20].

Fig. 5 shows an aggregated daily (weekday, July) load profile for the three phases in feeder 4 (100 customers) and an example day of PV generation from 10 domestic customers.

\section{Case 1: Even PV Penetration}

The $P V$ penetration in this paper is calculated by the number of customers having PV systems in relation to the total number of customers. For instance, a 30\% PV penetration means that 105 out of the 351 households have PV systems installed. The corresponding aggregated maximum generation peak would be approximately $300 \mathrm{~kW}$ which, in this case, is almost equivalent to the peak demand of the network. During minimum demand (circa $150 \mathrm{~kW}$ ), however, this relatively small penetration would result in reverse power flows. For the studied LV network, an even PV penetration of 70\% (i.e., 246 PV systems installed) was considered as the highest possible given that the peak reverse power reaches the transformer rating. No thermal overloads are experienced by the feeders at this penetration.

For comparison purposes, the network equipped with offload tap changer is also analyzed considering a suitable tap position to cope with PV systems (+2.5\%, i.e., L-N $244 \mathrm{~V})$. Fig. 6 shows a daily (weekday, July) voltage profile at the busbar and far end customers with a 70\% PV penetration. For this day, the voltage at the busbar is approximately 242 to $247 \mathrm{~V}$ (1.05 to $1.07 \mathrm{pu}$ ). The maximum voltage drop along the feeder during peak is $\sim 10 \mathrm{~V}(0.04 \mathrm{pu})$. The highest voltage rise due to PV systems is also $\sim 10 \mathrm{~V}$. Voltages at the far end customers in feeders 4 and 6 exceed the upper limit of $253 \mathrm{~V}$.

\section{1) Week-Long Power Flow Simulation}

Fig. 7, Fig. 8, and Fig. 9 show the profiles for a week in July (summer) with a 70\% PV penetration for the CSC, TBC and RMC strategies, respectively. The set-point voltage, the corresponding tap position and the busbar voltage profiles are plotted. The bandwidth used in all simulations was $2.2 \%$.

For the RMC, 5, 15 and 30-min control cycles are investigated in this paper. 5-min is considered as the shortest control cycle so as to cater for the communication and tap operation delay times. Detailed results for the 30-min control cycle are presented in Fig. 9. For the studied summer week, the CSC, TBC and RMC strategies resulted in 8.3, 7.7 and 5.4\% of the 351 customers non-compliant with BS EN50160 voltages. This shows a clear improvement when adopting the remote monitoring, particularly in comparison with the off-load tap changer $(41.5 \%)$. In terms of the usage of the OLTC, the three control strategies required 114, 80 and 19 tap changes, respectively. In this case, the RMC resulted in just a fraction of the tap changes needed by the other two strategies.

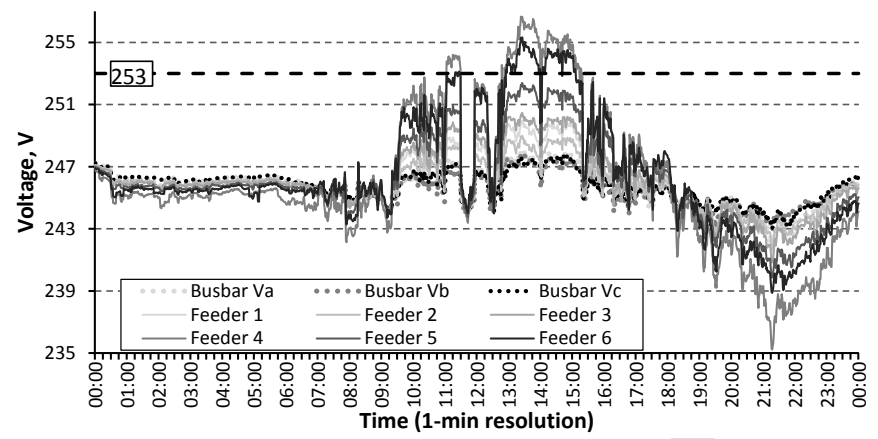

Fig. 6. Daily (weekday, July) voltage profiles at busbar and far end customer with $70 \%$ PV systems - off-load tap changer

TABLE III

SEASONAL AND ANNUAL PERFORMANCE OF A WEEK-LONG ANALYSIS

\begin{tabular}{|c|c|c|c|c|c|}
\hline Metric & $\begin{array}{c}\text { Control } \\
\text { strategies }\end{array}$ & Summer & Spring/Autumn & Winter & $\begin{array}{l}\text { Annual } \\
\text { average }\end{array}$ \\
\hline \multirow{6}{*}{$\begin{array}{c}\text { Non- } \\
\text { compliant } \\
\text { customers, } \\
\% \\
\text { (in a week) }\end{array}$} & $\begin{array}{l}\text { Off-load tap } \\
\text { changer }\end{array}$ & 41.5 & 25.4 & 8.0 & 25.1 \\
\hline & $\mathrm{CSC}$ & 8.3 & 0.9 & 0 & 2.5 \\
\hline & TBC & 7.7 & 0 & 0 & 1.9 \\
\hline & RMC (5-min) & 1.4 & 0 & 0 & 0.4 \\
\hline & RMC (15-min) & 0.85 & 3.1 & 0.85 & 2.0 \\
\hline & RMC (30-min) & 5.4 & 4.3 & 0.3 & 3.6 \\
\hline \multirow{5}{*}{$\begin{array}{c}\text { Daily } \\
\text { average } \\
\text { no. of tap } \\
\text { changes }\end{array}$} & CSC & 16.3 & 12.3 & 4.9 & 11.5 \\
\hline & $\mathrm{TBC}$ & 11.4 & 9.1 & 10.3 & 10.0 \\
\hline & RMC (5-min) & 4.4 & 4.6 & 2 & 3.9 \\
\hline & RMC (15-min) & 3.3 & 2.7 & 1.3 & 2.5 \\
\hline & RMC (30-min) & 2.7 & 3.4 & 1.4 & 2.8 \\
\hline
\end{tabular}

The performance metrics of the week-long analysis are shown in Table III. The season-weighted (i.e., annual) average is calculated by adopting a weight of $25 \%$ for summer, $25 \%$ for winter, and $50 \%$ for spring/autumn. For the analyzed PV penetration of $70 \%$, the TBC strategy resulted in a better mitigation of voltage issues and also a smaller number of tap changes than CSC. However, the RMC strategy resulted in the best performance for mitigating voltage issues and with only $30 \%$ of the tap operations needed by CSC or TBC.

\section{2) Monte Carlo Analysis}

The annual average performance metrics for the Monte Carlo analysis are shown in Fig. 10 and Fig. 11. As seen in Fig. 10 , with the off-load tap changer customers present voltage issues from 30\% PV penetration. However, with the OLTC, disregarding the control strategy, it is only until $50 \%$ of PV penetration that customers might experience voltage problems. $\mathrm{TBC}$ has a better performance of voltage mitigation than CSC, but at expense of more tap changers. Considering the voltages and the use of the OLTC, the RMC strategy outperformed the CSC and TBC. In terms of control cycles, the 5-min control cycle resulted in fewer non-compliant customers but required more tap changes than the other two control cycles.

\section{Case 2: Uneven PV Penetration and Capacitor Banks}

\section{1) Settings of Capacitor Banks}

In reality PV systems can be unevenly distributed among feeders. Here, uneven PV penetrations are created by allocating PV systems only to feeders 3, 4 and 5. Penetrations are relative to customers in these feeders only, from 0 to $100 \%$. No thermal overloads are experienced by these feeders. 


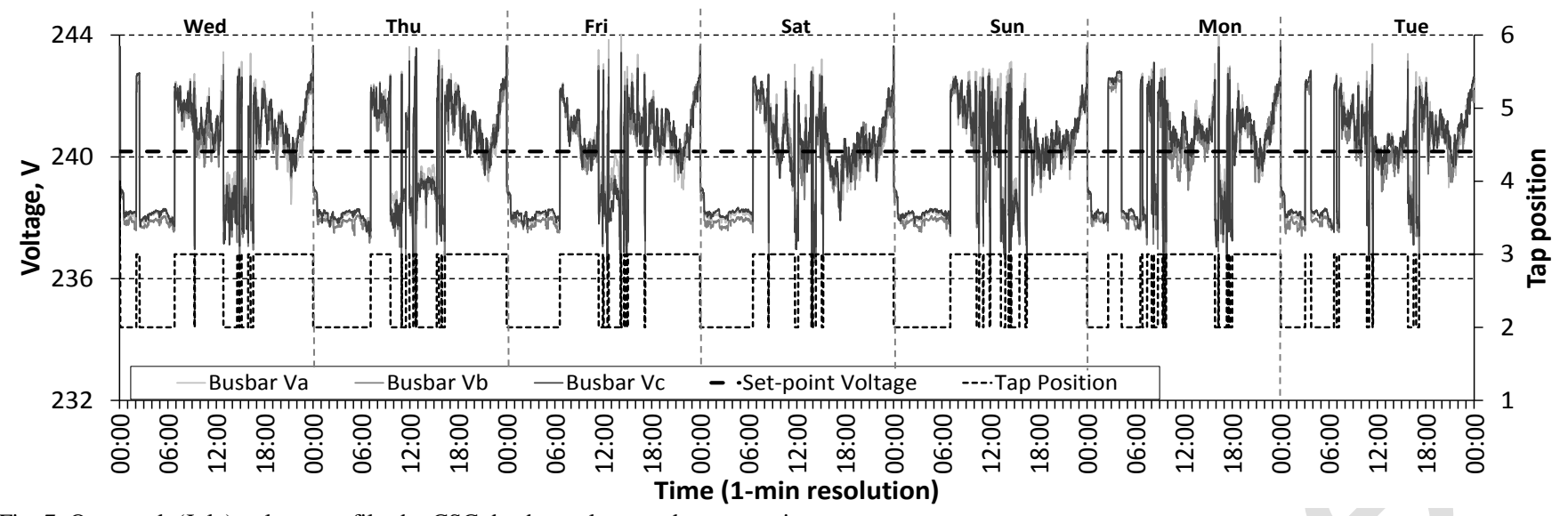

Fig. 7. One-week (July) voltage profiles by CSC: busbar voltage and tap operations

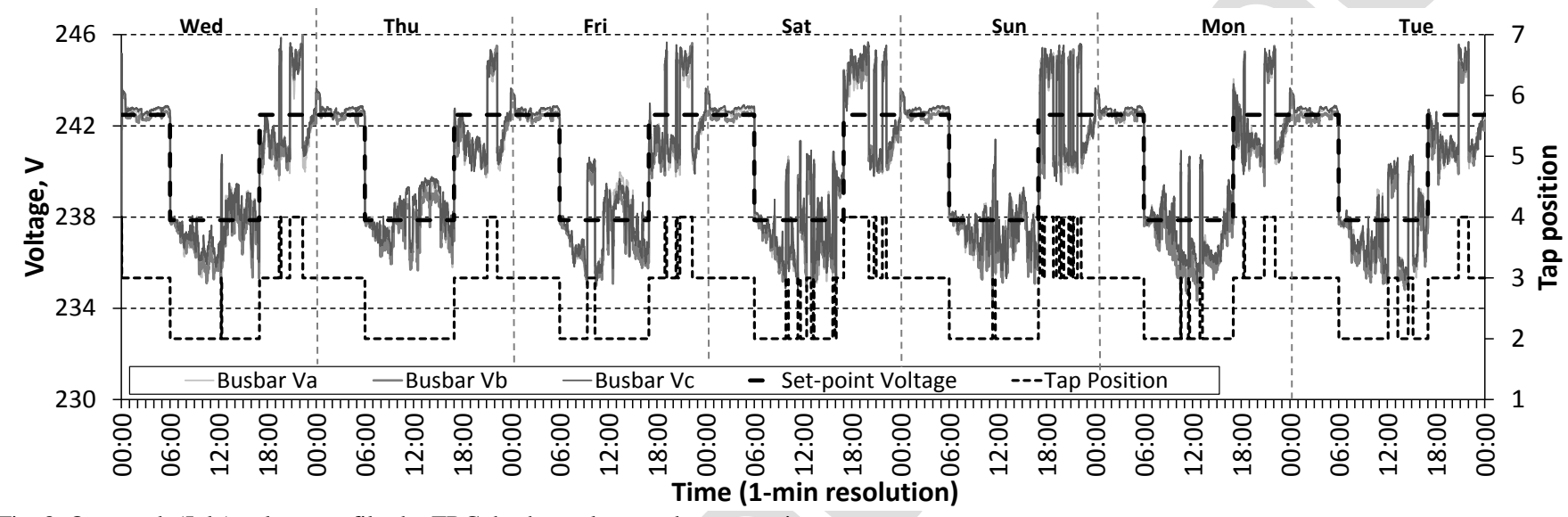

Fig. 8. One-week (July) voltage profiles by TBC: busbar voltage and tap operations

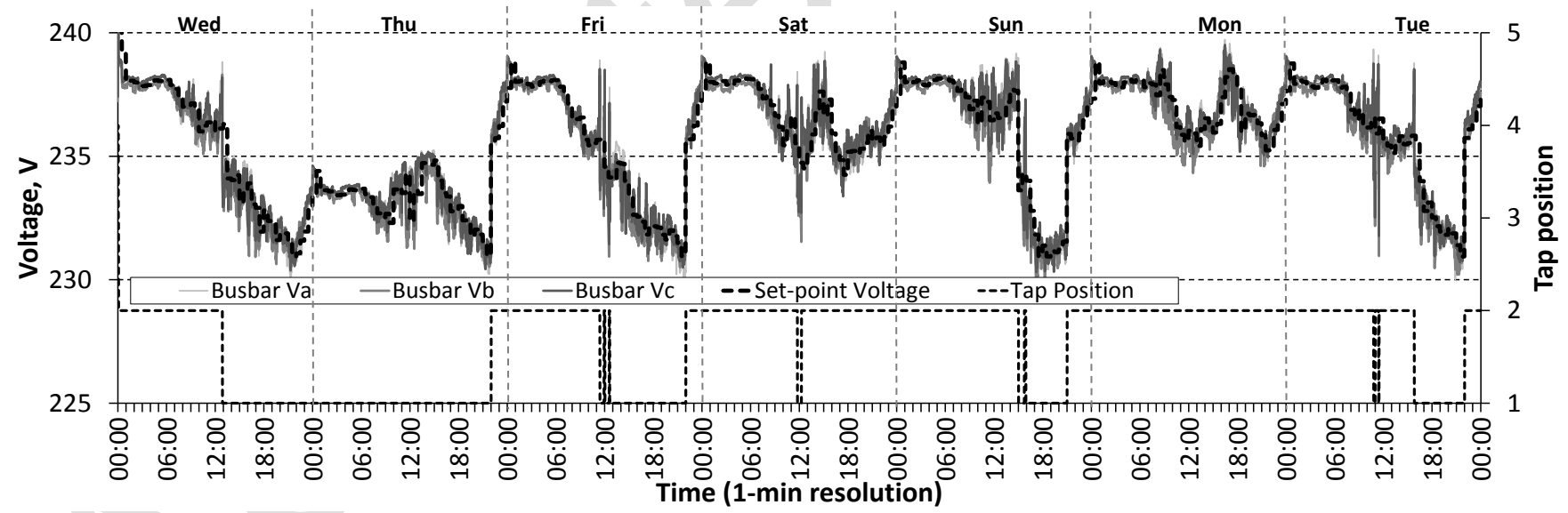

Fig. 9. One-week (July) voltage profiles by RMC, 30-min control cycle: busbar voltage and tap operations

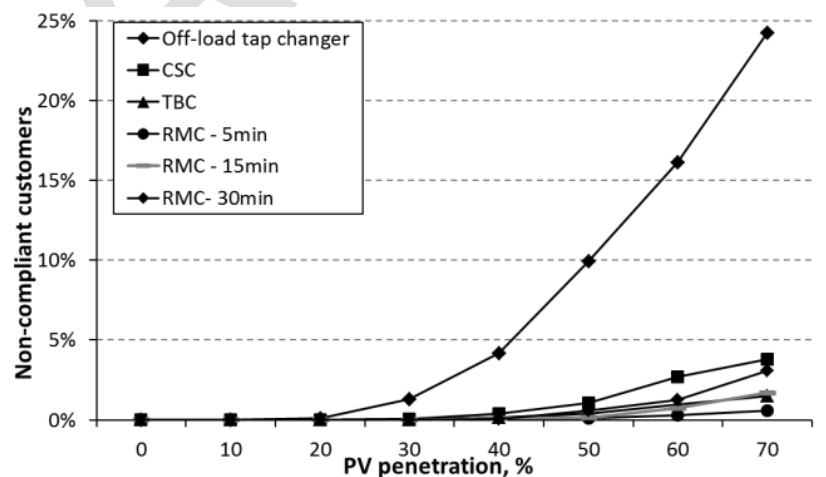

Fig. 10. Average customers with voltage problems - even PV penetration

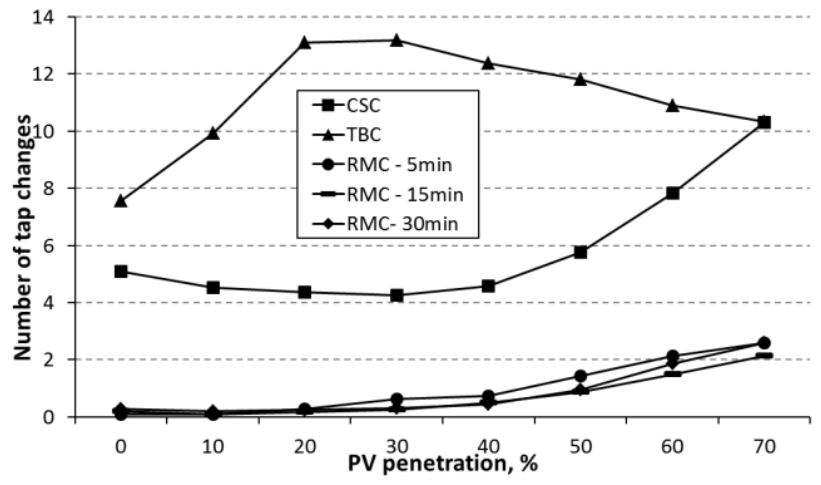

Fig. 11. Daily average number of tap changes - even PV penetration 


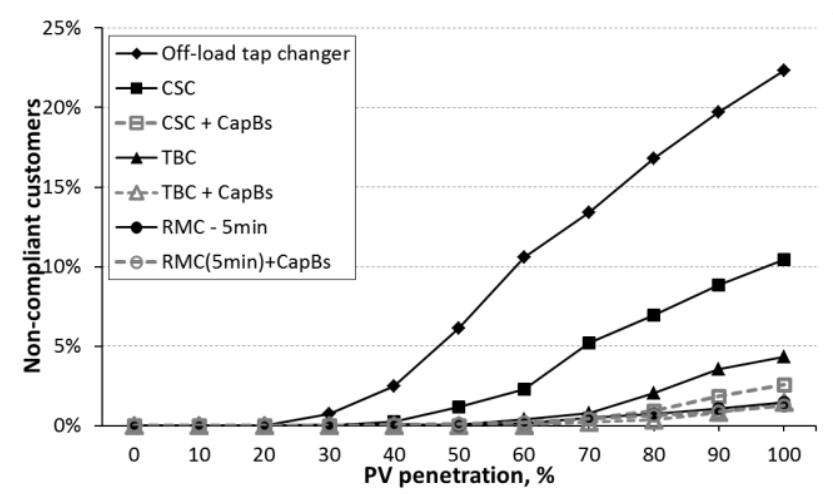

Fig. 12. Average customers with voltage problems - uneven PV penetration

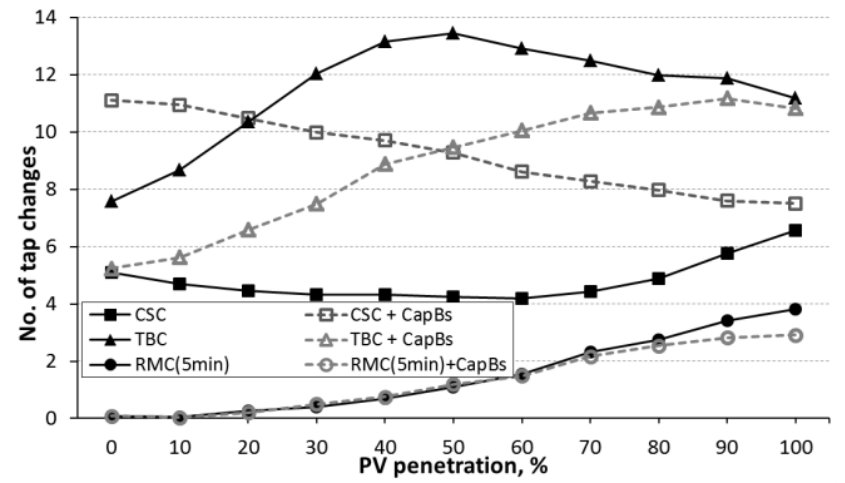

Fig. 13. Daily average number of tap changes - uneven PV penetration

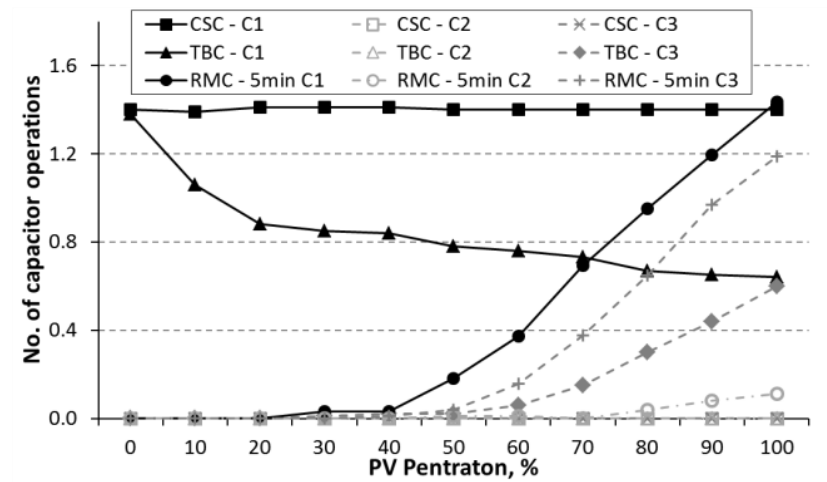

Fig. 14. Average capacitor operations - uneven PV penetration

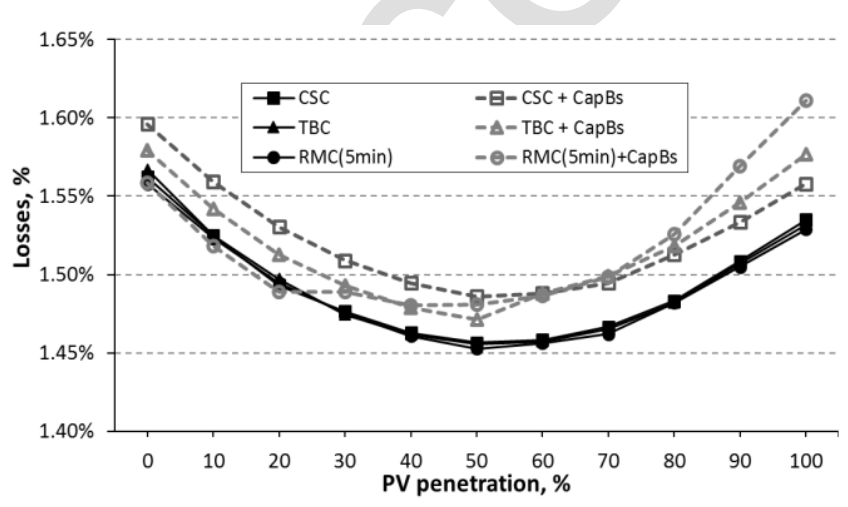

Fig. 15. Average daily energy losses for different control strategies with and without capacitors

All the three capacitor banks (i.e., $\mathrm{C}_{1}, \mathrm{C}_{2}$ and $\mathrm{C}_{3}$ ) are threephase with a rating of $50 \mathrm{kVAr}(16.7 \mathrm{kVAr}$ per phase). These capacitors will provide a maximum voltage gain (all three banks $\mathrm{ON})$ of $\sim 4.5 \mathrm{~V}$ at the connection points. This results in a voltage boost at the busbar of $\sim 3 \mathrm{~V}$ which is lower than one tap from the OLTC $(4.6 \mathrm{~V})$, hence allowing for coordination.

The most suitable switch-on and switch-off voltages are found to be $228.6 \mathrm{~V}$ and $236.6 \mathrm{~V}$, respectively. This considers keeping the voltage at the feeder far end higher than the lower limit of $216 \mathrm{~V}$ with necessary headroom and an adequate deadband. On the other hand, to coordinate with the OLTC (tap operation delay $120 \mathrm{~s}$ ), the switch-on delays of $C_{1}, C_{2}$ and $C_{3}$ are $30,60,90 \mathrm{~s}$, respectively, and the switch-off delays are 90 , 60 and $30 \mathrm{~s}$, respectively.

\section{2) Monte Carlo Analysis}

The annual average performance metrics for the Monte Carlo analysis are shown in Fig. 12, Fig. 13 and Fig. 14 (RMC with 5-min control cycle presented). Fig. 12 shows the noncompliant customers without and with the use of capacitor banks. The corresponding daily average numbers of tap and capacitor operations are shown in Fig. 13 and Fig. 14.

For the case of off-load tap changer $(+2.5 \%)$, no switching of the capacitors occurred and the number of non-compliant customers remained the same. This is because voltages were relatively high throughout the day and thus capacitor banks were not needed. Different off-load tap settings should be investigated to exploit any potential benefit from capacitors, this work is done in [21].

On the other hand, for all the OLTC-based control strategies, the use of capacitors significantly decreased the number of noncompliant customers. In terms of tap changes, the coordinated use of capacitors reduced the number of tap changes for the RMC and TBC cases. This is because the capacitors were set with shorter delays than the OLTC, and hence low voltage issues could be fixed before needing tap operations. Nonetheless, this was not the case for CSC given that the capacitors led to voltages at the busbar higher than the fixed setpoint, thus increasing the tap operations. In terms of capacitor switching actions, the capacitor in feeder $4\left(C_{1}\right)$ operated more times than the other two due to the higher loading of the feeder.

The daily energy losses of the studied network with and without capacitor banks are shown in Fig. 15. Considering only the household demand (i.e., no PV systems and no capacitor banks), the average daily energy losses are $46.2 \mathrm{~kW}$, which corresponds to approximately $1.5 \%$ of the energy consumption. As the PV penetration increases, ' $U$ ' shapes are observed. For small penetration levels the corresponding generation reduces the net demand and hence results in lower network losses. With higher penetrations, however, reverse power flows appear and become as large as the net demand.

For the CSC and TBC, the use of capacitors resulted in a slight increase in losses for all PV penetrations. For the RMC, the use of capacitors increases the losses for penetrations higher than $30 \%$. These findings are aligned with the capacitor operations shown in Fig. 14. Nonetheless, the use of capacitors only increased the energy losses by less than $0.1 \%$ in average. This limited effect is due to the relatively small capacitor size adopted in the study (50 kVAr) as well as to the control logic which uses the capacitors only when needed. 


\section{Performance of THE LoVIA Project}

Each of the two residential LV networks part of the "Low Voltage Network Integrated Automation (LoVIA)" project has 6 feeders and a PV penetration of approximately $30 \%$ [11]. The RMC strategy was implemented on the two networks in May 2014. The adopted settings include an OLTC bandwidth of 4.4\% (less sensitive than in the simulations), a tap operation delay of 120 seconds, and a control cycle of 30 minutes. Deployed capacitor banks did not operate due to the almost even distribution of PV installations among feeders.

The daily behaviour of the real OLTC-fitted transformer in network one is shown in Fig. 16. The set-point, measured busbar voltage (L-N), and the corresponding tap position are plotted. As it can be verified, when using the RMC strategy, the busbar voltage follows the set-point required to compensate remote voltages.

Fig. 17 presents the monitoring voltages at the busbar as well as the end points of the feeders for the same day. It can be seen from Fig. 16 and Fig. 17 that, when the aggregated household demand increased at 07:00 (i.e., greater voltage drops), the deployed control logic led to a significant increase in the setpoint. As a result, the OLTC had one tap operation (from position 4 to 5) to increase the voltages of the LV feeders. When the demand decreased (due to PV generation and/or lower demand), a lower set-point was given, moving the tap back to position 4 at around 09:30. A similar process happened in the evening (from 18:30 to 22:00).

The monitoring data from the LoVIA project was limited to 5 and 10 weeks for networks one and two, respectively. The corresponding analysis found that voltages at all monitoring points of the LV feeders were within statutory limits. In addition, throughout these periods, there were 50 tap operations (1.4 per day on average) in network one and 136 (1.9 per day on average) in network two. Although the bandwidth adopted was twice larger than that of the simulations, thus making the control less sensitive, the overall performance was aligned with the findings presented in Fig. 10 and Fig. 11 (for 30\% of PV penetration and 30-min control cycle). Further analyses carried out on the monitoring data are documented in the LoVIA project reports [11].

\section{DISCUSSION}

In the UK, residential customers (mostly single-phase connected) can only install PV generation systems rated up to 16A (according to the Engineering Recommendation G83/1 [20]). Consequently, most installations tend to adopt, when possible, capacities between 3 and $4 \mathrm{kWp}$ [22]. Therefore, in the UK context, defining PV penetrations in LV networks based on the number of customers with PV installations is an intuitive and straightforward approach [23]. Nonetheless, care should be taken when adopting this definition in regions or countries where households can have very different PV capacities due to two and/or three-phase connections.

Although one particular OLTC design was considered in this work, the benefits from different numbers of taps and step sizes can also be explored. This is a topic worth addressing given that it can provide manufacturers and DNOs with guidelines for the design and operation of future LV networks.

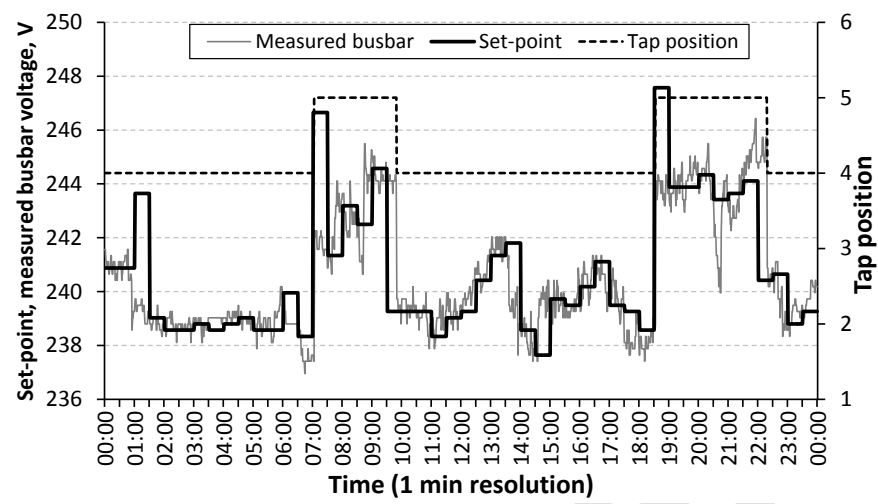

Fig. 16. Actual one-day tap operation of the OLTC in network one of LoVIA

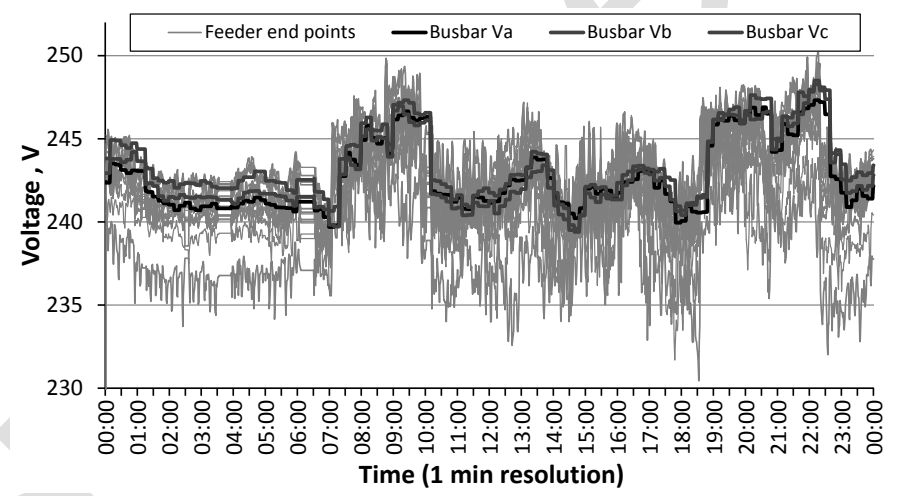

Fig. 17. Monitoring voltages on the same day as shown in Fig. 16

A bandwidth of $2.2 \%$ was used in all simulations in this work. Different bandwidths may result in different voltage profiles and different number of control actions. However, the findings are expected to be similar for other bandwidths.

For a deterministic analysis, the results are limited to the specific week analyzed and therefore cannot be generalized. For example, due to the uncertainties of PV generation and demand, results could vary in different weeks. These uncertainties, however, are catered for when adopting the Monte Carlo analysis. Therefore, by using this probabilistic approach it is possible to quantify the performance of the control strategies in a more realistic manner.

The capacitor banks were considered to work on a decentralized mode and the coordination was achieved by the time delays of the various devices. Aspects of the proposed control strategy can be incorporated in a centralized optimization framework that could be used as a benchmark.

In practice, voltage variations from the medium voltage (MV) network influence the primary of the LV transformer and therefore have an impact on the OLTC operation. The proposed analysis can be extended to understand this and other interactions by considering integrated MV-LV models.

\section{CONCLUSIONS}

Three control strategies, constant set-point, time-based and remote-monitoring based, have been proposed to mitigate voltage rise issues in PV-rich LV networks using OLTC-fitted transformers. A real UK LV network was used to assess the performance of each control strategy considering 1-min resolution simulations. A Monte Carlo approach carrying out 
week-long three-phase power flows was adopted to cater for the uncertainties surrounding domestic PV generation and loads as well as the inherent unbalance resulting from single-phase connections.

The results show that with the OLTC, the occurrence of voltage problems was delayed to $50 \%$ of $\mathrm{PV}$ penetration (even among feeders) from $30 \%$ when using off-load tap changer. The remote monitoring-based control can significantly enhance the network's ability to host PV systems whilst limiting tap operations and voltage issues. Nonetheless, the time-based control resulted in a comparable performance in terms of voltages and hence can be considered as a potential solution without the need of remote monitoring - although at the expense of more tap operations.

The analysis also shows that for LV feeders having contrasting voltage issues, due to uneven PV penetrations, capacitors can be adopted operating on a coordinated but yet decentralized mode. The capacitor banks can increase further the network's ability to host larger penetrations of PV systems.

This framework can be adopted by industry to assess the benefits from OLTC-based solutions in future LV networks.

\section{REFERENCES}

[1] UK Solar PV Strategy Part 1: Roadmap to a Brighter Future, Department of Energy and Climate Change (DECC), Oct. 2013.

[2] UK Solar PV Strategy Part 2: Delivering a Brighter Future, Department of Energy and Climate Change (DECC), Apr. 2014.

[3] C. Reese, C. Buchhagen, L. Hofmann, "Voltage range as control input for OLTC-equipped distribution transformers," in IEEE PES T\&D Conf. and Expo., 2012, pp. 1-6.

[4] C. Reese, C. Buchhagen, L. Hofmann, "Enhanced method for voltage range controlled OLTC-equipped distribution transformers," in IEEE PES General Meeting, 2012, pp.1-8.

[5] T. Stetz, F. Marten and M. Braun, "Improved low voltage grid-integration of photovoltaic systems in Germany," IEEE Trans Sustainable Energy, vol. 4, pp. 534-542, Apr. 2013.

[6] T. Stetz, K. Diwold, M. Kraiczy, D. Geibel, S. Schmidt and M. Braun, "Techno-economic assessment of voltage control strategies in low voltage grids," IEEE Trans Smart Grid, vol. 5, pp. 2125-2132, Jul. 2014.

[7] P. Wang, D.H. Liang, J. Yi, P.F. Lyons, P.J. Davison and P.C. Taylor, "Integrating electrical energy storage into coordinated voltage control schemes for distribution networks," IEEE Trans Smart Grid, vol. 5, pp. 1018-1032, Mar. 2014.

[8] C. Körner, M. Hennig, R. Schmid and K. Handt, "Gaining experience with a regulated distribution transformer in a smart grid environment," in CIRED Workshop, 2012, pp. 1-4.

[9] A. Navarro and L. F. Ochoa, "Increasing the PV Hosting Capacity of LV Networks: OLTC-Fitted Transformers vs. Reinforcements," In IEEE PES ISGT 2015, USA. Feb. 2015.

[10] C. Long, A. T. Procopiou, L. F. Ochoa, G. Bryson and D. Randles, "Performance of OLTC-based control strategies for LV networks with photovoltaics," IEEE PES General Meeting, Colorado, USA. Jul. 2015.

[11] Electricity North West Ltd (2015, Aug. 28). Low Voltage Integrated Automation (LoVIA) [Online]. Available: http://www.enwl.co.uk/aboutus/the-future/lenf-tier-1-nia/lovia
[12] Voltage characteristics of electricity supplied by public electricity networks, BS EN50160, 2010.

[13] A. Navarro and L.F. Ochoa, "Probabilistic impact assessment of low carbon technologies in LV distribution systems," IEEE Trans Power Syst., 2013 , in press.

[14] MR, (2013, Dec.). "GridCon, Transformer-The voltage regulated distribution transformer," [Online]. Available: http://www.reinhausen.com/desktopdefault.aspx/tabid-1516/1835_read$4652 /$.

[15] R.A. Gallego, A.J. Monticelli and R. Romero, "Optimal capacitor placement in radial distribution networks," IEEE Trans Power Syst., vol.16, pp. 630-637, Nov. 2001

[16] G. Carpinelli, P. Varilone, V. Di Vito and A. Abur, "Capacitor placement in three-phase distribution systems with nonlinear and unbalanced loads," Proc. Inst. Elect. Eng., Gen. Transm. Distrib, vol. 152, pp. 47-52, Jan. 2005

[17] H.M. Khodr, F.G. Olsina, P.M. De Oliveira-De Jesus and J.M. Yusta , "Maximum savings approach for location and sizing of capacitors in distribution systems," Electric Power Syst. Research, vol. 78, pp. 11921203, Jul. 2008

[18] I. Richardson, M. Thomson, D. Infield and C. Clifford, "Domestic electricity use: a high-resolution energy demand model," Energy and Buildings, vol. 42, pp.1878-1887, Oct. 2010.

[19] Office for National Statistics. (2013, Nov. 22). Statistical Bulletin: Families and Households, 2013, [Online]. Available: http://www.ons.gov.uk/ons/dcp171778_332633.pdf.

[20] Recommendations for the Connection of Small-scale Embedded Generators (up to 16 A per phase) in Parallel with Public Low-voltage Distribution Networks, Engineering Recommendation G83/1, Sep. 2003.

[21] C. Long, L. F. Ochoa, G. Bryson and D. Randles, "Adoption of capacitors in LV networks with PV systems," in CIRED, $20^{\text {th }}$ Int. Conf. Exhibition Electricity Distribution, Lyon, France, Jun. 2015.

[22] A. Navarro, L. F. Ochoa, and D. Randles, "Monte Carlo-based assessment of PV impacts on real UK low voltage networks, " in IEEE PES General Meeting, 2013, pp. 1-5.

[23] Electricity North West Limited, "Low Carbon Solution Project: "closedown report'," 2015 [Online]. Available: http://www.enwl.co.uk/about-us/the-future/lcnf-tier-1-nia/low-voltagenetwork-solutions.

\section{BIOGRAPHIES}

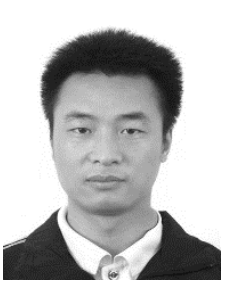

Chao Long (S'11, M'15) received the B.Sc. degree from Wuhan University, China in 2008 and Ph.D. degree from Glasgow Caledonian University, UK in 2014. He was a research associate in The University of Manchester, UK from August 2013 to May 2015 and is currently a research associate in Cardiff University, UK. His research interests are areas of distributed generation and plug-in electric vehicles.

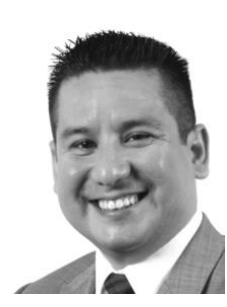

Luis F. Ochoa (S'01, M'07, SM'12) received the B.Eng. degree from UNI, Lima, Peru, in 2000 and the M.Sc. and Ph.D. degrees from UNESP, Ilha Solteira, Brazil, in 2003 and 2006, respectively. He is a Senior Lecturer in Smart Distribution Networks at The University of Manchester, UK. His current research interests include network integration of distributed energy resources and future low-carbon distribution networks. 